\title{
An Overview of Wettability Measurements in Fractured Carbonated Reservoir and Investigate the Effects of Wettability Changes in the Optimization of Enhanced Oil Recovery Techniques
}

\author{
Afshin Davarpanah ${ }^{\mathrm{a} *}$, M.Mehdi Nassabeh ${ }^{\mathrm{b}}$, Mojtaba Zarei $^{\mathrm{c}}$ \\ ${ }^{a}$ Department of petroleum Engineering, Science and Research Branch, Islamic Azad University, \\ Tehran, Iran \\ ${ }^{b}$ Department of Petroleum Engineering, Faculty of Engineering and Technology, Omidiyeh Branch, \\ Islamic Azad university, Omidiyeh, Iran \\ ${ }^{c}$ Department of chemistry Engineering, Islamic Azad University, Shahreza, Iran
}

\begin{abstract}
Wettability is defined as rock tendency to spread or stick a fluid at rock's surface in presence of an immiscible liquid. In a water - oil rock system, wettability is defined base on amount of priority that stone surface cover with water or oil. Nearly, 50 percent of the world's oil reserves proven are located in carbonate reservoirs. The recovery factor in this reservoir is relatively low (less than 30\%). With regard to fractured Carbonate Reservoirs and also low permeability of matrix rock in reservoirs in contrast with sandstone reservoirs. Therefore, the potential of oil recovery methods is so high in these reservoirs. The common method to enhance oil recovery in conventional reservoirs (sandstone and carbonate reservoirs with water wet rock reservoir) is water injection in these reservoirs that could be increased reservoir oil production by holding up the reservoir pressure above the bubble point pressure as well as increasing sweep efficiency. In carbonate reservoir or oil - wet reservoirs rock this method has no effect because in contrast with sandstone reservoirs at around 80 to $90 \%$ of carbonate reservoirs have a low capillary force, or in other words tends to oil wet more. In this case, due to low capillary force, injected water has no ability to penetrate into matrix rock and this process is flowed without a significant amount of oil move in high permeable fractures and breakthrough occurs in a shorter time thus the recovery factor decreases consequently.
\end{abstract}

Keywords: wettability, oil recovery, fractured carbonate reservoirs, matrix rock

\section{INTRODUCTION}

The enhanced oil recovery idea with changing reservoir rock wettability process is not a new idea and is backed to Buckley and leveret studies in 1942. But recently this idea has been discussed as a topic of study. Mainly, these studies have included changing oil wet cores by thermal methods or adding surface-active fluids into water, simulation of fractured reservoirs operation and the effect of wettability [1,2]. Researches has shown results that cleaned carbonate rock has primary water wet wettability that rock wettability changed into oil wet by weakening aqueous layer on rocks and then oil absorption of stone surface. With regard to acid groups decomposition of oil in nonacidic $(\mathrm{pH}=8)$ carbonate reservoir zone, the reason of this wettability changing could be define as acidic fluid absorption (carboxylate) with negative charged on positive surface of carbonate rocks[3,4,5]. Therefore we can say, the wettability of rock not only depending on the properties of rock solid particles, but also depends on available fluid properties in system including crude oil and salt water. In other words, wettability should be considered as whole system properties. Above contents is important that, the efforts to achieve practical methods in order to making water wet carbonate rocks, require a correct understanding of initial rock wettability and its historic changes is by natural factors. Base on this information, it could be suggested that adding cationic fluids into injected water and anionic fluids absorption that attached to rocks by this fluids probably, leads to change wettability into water wetagain [6].

Wettability is one major factor of controlling position, flow and fluid distribution in reservoir. Nearly, all analyzes of capillary pressure, relative permeability, flooding behavior, third recovery simulation, 
irreducible water saturation, residual oil saturation and electrical properties are effected by a wettability of core. For these reasons and in order to accurate forecasts during core analyze tests, wettability should be similar with untouched reservoir rock wettability $[7,8]$.

\subsection{Classification of Wettability in Reservoir System}

Generally, the main and important fluids in reservoir are water, oil and gas since, usually there are gas, water, oil or non-wet fluid in one rock system, wettability in reservoirs is measured with water and oil and generally, it would be better if we use water-wet and oil-wet expression compare with other words. Depending on rock interactions with oil and water. rock, could be ranged from extremely water-wet to extremely oil-wet which is distributed on rock surface by water -wet and oil - wet definition respectively, and this word (extremely)is used when each of these fluids spread on rock surface completely and rock does not have any priority tendency compare with oil and water. Literally, from the view of neutral wettability. In addition, there are another wettability along neutral and extremely wettability which is called partial wettability $[9,10,11]$.

\subsection{Wettability Measuring}

A various methods could be found to measure rock wettability in the literatures and scientific articles. Such as contact angle, suction and obligation movement, suction rate, USBM, microscopic study (glass blade method), relative permeability curves, saturation - permeability correlations, capillary pressure curve and NMR methods that should be noted[12,13].

\section{Investigating The Effect of Thermal Enhance Oil Recovery Operation on Changes of WetTability}

Thermal method is one of the considerable enhanced oil recovery methods[14,15,16]. Although the most significant goal of thermal EOR operation is reducing viscosity, temperature increasing effects on other key variables Such as:

- Density

- viscosity of each phases

- interfacial oil properties

- Water

- Gas

- Surface tensions

- $\mathrm{pH}$

- Interfacial solid and liquid energy

- Oil characteristics

These transformations influence directly or indirectly on the motion of water, oil and gas phases in rock reservoir. In other words, the thermal energy imposed on the system due to thermal operations not only leading to fluid property changes and fluids interaction, but also effect on the interaction of the rock and fluid[17,18].These changes in surface and interfacial property of rock and fluids and fluid with fluid, changing in the composition of crude oil, salt water and mineral structure of the rock can directly and indirectly effect on the wettability system and change the wettability system properties. Therefore, knowing the thermal EOR methods that effects on wettability is necessary to optimize this performing procedure in reservoirs, especially, in fractured reservoir[19,20,21,22]. Reservoir rock wettability, which is had the water-wet condition in early time change into oil-wet condition with the polar substance absorption of crude oil on the surface. That this wettability alteration to oil-wet condition for carbonate rocks is higher which is concluded the carbonate reservoirs[23,24].Therefore, the absorption of these components on rock surface in fracture reservoirs leads to matrix oil-wet condition, which is leads to produce undesirable oil production conditions in imbibition mechanism. So performing some of the operations to change the undesirable matrix wettability condition for oil production from the matrix reservoir system in this reservoir are important and necessary that is too large of crude oil allocated in matrix system[25].

Thermal operations as an enhanced oil recovery method, not only effecting on crude oil viscosity reduction, that is the most important goal but also impact on the other parameters such as wettability. 
An Overview of Wettability Measurements in Fractured Carbonated Reservoir and Investigate the Effects of Wettability Changes in the Optimization of Enhanced Oil Recovery Techniques

Therefore, knowing of the effects of these operations on the wettability is necessary to optimize this operation. It should be mentioned that increasing System temperature resulting from vapor water action change the oil-wet condition to water-wet condition in surface of micro model.

\subsection{Investigating the Natural Factors of Initial Wettability Changing in Carbonate Rocks from Water Wet to Oil Wet Condition}

\section{Investigating the Effect of Asphalten on Rock Wettability}

One of the effective factors in initial reservoir rock wettability is acid fluid absorption in heavy oil parts including asphaltene on the surface of the water wet rock. Investigating this factor with laboratory methods requires knowing the exact values of parameters such as, the percentage of asphaltene, acidic and alkali ratio, etc. due to unavailable measurement facilities, this factor is investigated by qualitative method. For this purpose, a sample of crude oil with high viscosity is placed for 2 weeks in an open container since, the light components are separated.

The amount of oil remaining in container is used as rich oil asphaltene and heavy materials and normal hexane is used as oil model without asphaltene and sedimentary materials. We have made three oil samples with combination of two oil that above mentioned oil with a certain volume ratios. As it mentioned before, although the basic parameters of oil is unknown, the relative percentage of asphaltene could be controlled due to mixing of oil with a pure solvent (normal hexane). Thus, we have reduced the higher percentage of asphaltene by applying a greater percentage of normal hexane. Now, to compare the effect of each formed oil with wettability alteration ratio in carbonate rocks, moreover clean and dry blades locate for 24 hours in this oil. It should be noted that all cleaned samples have about 30 to 40 contact angle degrees. Which is almost lost all oil sediments during cleaning operation After ending locating time, blades remove from oil then after washing with toluene, take normal hexane within five seconds and distilled the water put them in contact angle measurement instrument and normal hexane and distilled water contact angle of surface stone is measured. Furthermore, the effect of asphaltene volume on wettability could be obtained by comparing the contact angles of various tests. The results of this experiment are shown in the figure below, and it is quite as expected as shown in figure. it can be deduced that wettability samples tends to be oil-wet more by increasing the percentage of asphaltene, It should be noted that, the contact angle for sample which is placed in normal hexane is approximately 30 degrees due to the fact cleaned sample had 30 and 40 contact angle degree before locating in oil. It could be concluded that the sample which is placed in normal hexane has no effect on the wettability. However, the sample placing in heavy crude oil has become oil-wet extremely. Because the hexane drop on the surface of stone is expanded completely. For samples placing in three other oil samples having different percentage of asphaltene, the result angle is between two states which is shown that contact angle will be increased by increasing the relative percentage of asphaltene.

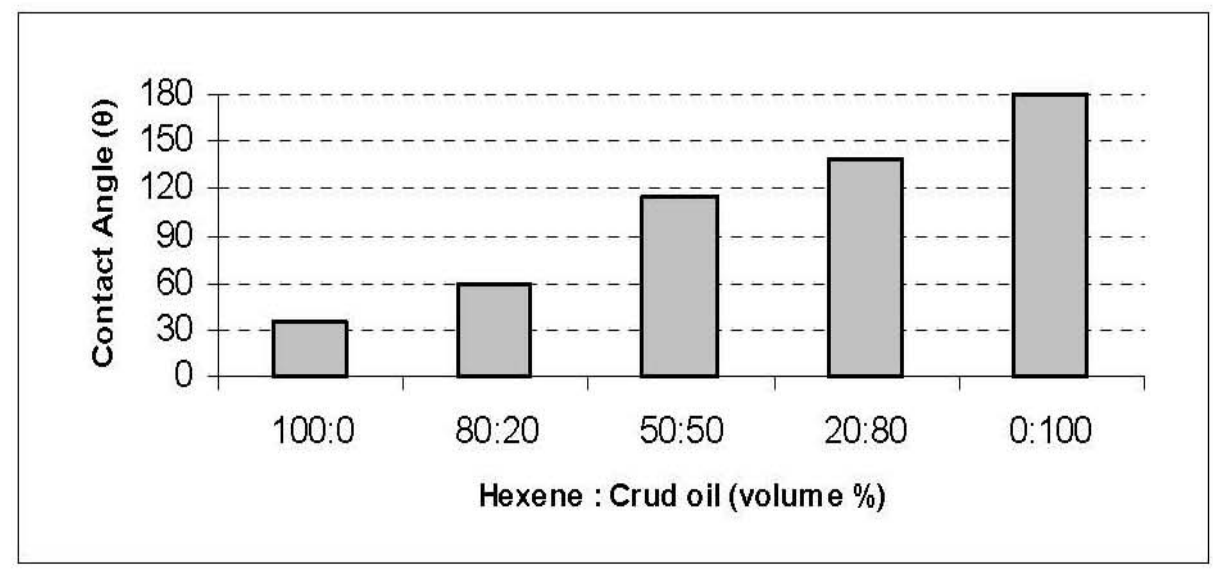

Figure1. The contact angle increases with surging crude oil- normal hexane ratio

\subsection{The Effect of Ph on Wettability in Carbonate Rock}

As it mentioned before, from electrostatic view the negative acid groups abortion in heavy oil parts on the surface of carbonate rocks, is a function of the electrical load on rock surface and acidic ratio. In the pervious section the effects of heavy materials and asphaltene examined on rock wettability. The 
results showed that samples wettability tend to oil wet condition with increasing asphaltene it should be noted that normal hexane was used for mixing with crude oil to reduce asphalteneratio, obviously, the acidic and asphaltene ratio decrease with increasing normal hexane ratio. in addition, it can be deduced that the acid degree ratio for net normal hexane is zero thus, it can be concluded that rock oilwet increase by surging the acidic crude oil ratio. Without doubt, this conclusion according to test results is not complete. The reason is that not only occurring the percentage of asphaltene and acidic degree reduction in oil is possible but also, other parameters might be changed. Among which it could mentioned the oil sample alkaline ratio. On the other hand other experiments results of researchers have shown that carbonate rock samples wettability is a function of the acidic oil ratio and the alkaline oil ratio has no effect on it. According to these issues, an experiment was decided to done under the effect of $\mathrm{pH}$ on rock wettability subject. The aim of this study was to assess the $\mathrm{pH}$ in addition, the effect of rock electric charge transformation with maintaining acidic oil ratio was investigated instead of changing the acidic oil ratio. It could be concluded that wettability change in pervious test was independent of the acidic and alkaline ratio of oil. If there is no wettability change in rock. Moreover, if wettability changes is shown, it could be connected that, depending on the type of changes in each acidic or alkaline ratio parameters. As mentioned, this experiment is done to ensure the accuracy of testing and results in two groups of three cleaned rocks sample that the obtaining results show the reliability of this method and results.

\section{RESULTS}

According to recent tests it could be concluded that asphaltene and heavy materials in oil are the efficient factors of wettability in carbonate rocks moreover, contact angle increases in linear trend by surging the percentage of this ingredients in crude oil. It could be said that the wettability change from an initial water-wet to oil-wet condition is due to absorption and deposition of this material on surface of rock. The results of these experiments is shown that if the rock surface charge is more, the absorption of this oil and oil-wet property increase consequently. The result is that absorbed oil on the surface of the rock are mostly negative charge materials. This material could be included fatty acids and carboxyl groups in oil. Usually, the absorption of this material is happen so fast and the existence of water on rock wall leads to reaction delay but it cannot prevent oil fluid from absorption of rock surfacecompletely.

\section{Conclusion}

(1) Asphaltene and acidic ratio of oil is one of the effective factors in wettability of carbonate rocks. the effect of these factors depends on surface charge in carbonate rocks and the impact of these factors increase by more surging of positive surface charge in carbonate rock with low $\mathrm{PH}$, it can be concluded that the negative groups absorption in oil on the positive surface of carbonate rock lead to change the rock wettability from oil-wet to water-wet condition.

(2) The presence of cationic surfactants in injected water can change the wettability of carbonate rocks to water-wet condition. These materials lead to separation by their combination with negative groups (which is attached to rock) and forming pair's ions.

(3) In contrast with anionic surfactants increasing temperature in presence of cationic surfactant lead to surging water and oil tension. Consequently, more water penetrate to rock by increasing the capillary force.

(4) Sulfate ions in injected water at high temperatures have a significant impact on the water-wet condition in carbonate rocks. High combination tendency of sulfate ions with carbonate rocks at high temperatures and competition with negative ions which is attached to rock lead to separation of them and more water-wet tendency in carbonate rocks.

\section{Suggestions}

The following suggestions are offered and continued to improve the quality of result test:

1. The results is shown that heavy material and asphaltene in oil and the acidic ratio in crude are two significant parameters in wettability change of carbonate rocks. With regard to performed experiments, the accessibility of different crude oil with certain property is not appropriate such as the exact amount of asphaltene and acidic ratio, therefore, the effects of these factors were completely reviewed inquality view. In addition, it is highly recommended that, this test is performed by applying 
An Overview of Wettability Measurements in Fractured Carbonated Reservoir and Investigate the Effects of Wettability Changes in the Optimization of Enhanced Oil Recovery Techniques

different percentages of crude oil with different asphaltene ratio. Also, the acidic ratio that is used could be change by adding fatty acids, artificially.

2. Due to influence surge of cationic surfactants and sulfate ions on wettability alteration of carbonate rocks by temperature increase and the tendency of carbonate rocks to more water wet at very high temperatures, are predicted. The combination of these two factors, (material injection at very high temperatures) have extra effect on wettability in carbonate rock. This item could be studied by spontaneous suction experiments. Moreover, the main problem in this tests is evaporation and boiling injected water at high temperatures which is solved by making stainless steel vacuum cells and putting pressure on injection system in addition pressure conditions will be close to real conditions of the reservoir.

\section{REFERENCES}

[1] E.J. Peters, Petrophysics, Department of Petroleum \&Geosystem's Engineering The University of Texas at Austin, USA, 2011.

[2] Kh Jarrahian, O. Seiedi, M. Sheykhan, M. VafaieSefti, ShAyatollahi, Wettability alteration of carbonate rocks by surfactants: a mechanisticstudy, Colloids Surfaces APhysicochem. Eng. Aspects 410 (1) (2012) 1e10.

[3] D. Tiab, E.C. Donaldson, Petrophysics: Theory and Practice of Measuring Reservoir Rock and Fluid Transport Properties, second ed., Elsevier, New York, USA, 2004, pp. 313e414.

[4] M. Salehi, Enhancing the Spontaneous Imbibition Process in Naturally Fractured Reservoirs through Wettability Alteration Using Surfactants: Mechanistic Study and Feasibility of Using Biosurfactants Produced from Agriculture Waste Streams, Ph. D. Thesis, Department of Chemical and Petroleum Engineering of Lawrence, University of Kansas, Kansas, USA, 2007.

[5] C.C. Heut, Semi-analytical Estimates of Permeability Obtained from Capillary Pressure, M.Sc. Thesis, Texas A\&M University, USA, 2005.

[6] C.L. Vavra, J.G. Kaldi, R.M. Sneider, Geological applications of capillarypressure: a review, AAPG Bull. 76 (1992) 840e850.

N. R. Morrow, "Wettability and Its Effect on Oil Recovery", SPE 21621, 1990.

[7] V. Jain, S. Brayant, and M. Sharma, "Influence Of Wettability and Saturation on Liquid-Liquid Interfacial Area in Porous Media", Environ. Sci. Technol., 37 (2003) 584-591.

[8] E. C. Lin, and E. T. S. Huang, "The Effect of Rock Wettability on Water Blocking During Miscible Displacement", SPE 17375, 1990.

[9] U. Karabakal and S. Bagci, "Determination of Wettability and Its Effect onWaterflood Performance in Limestone Medium", Energy \& Fuels, 18 (2004) 438-449.

[10] M-H. Hui and M. J. Blunt, "Effects of Wettability on Three-Phase Flow in Porous Media", J. Phys. Chem., 104 (2000) 3833-3845.

[11] N. Shahidzadeh-Bon, E. Bertrand, J. P. Dauplait, J. C. Borgotti, P. Vie, and D.Bonn, "Gravity Drainage in Porous Media: the Effect of Wetting", J. Pet. Sci.Eng., 39 (2003) 409-416.

[12] Y. Melean, D. Broseta and R. Blossey, "Imbibition Fronts in Porous Media:Effects of Initial Wetting Fluid Saturation and Flow Rate", J. Pet. Sci. Eng., 39(2003) 327-336.

[13] W. G. Anderson, "Wettability Literature Survey-Part 3: the Effects of Wettability on the Electrical properties of Porous Media", SPE 13934, 1986.9. W. G. Anderson, "Wettability Literature Survey-Part 4: Effects of Wettability on Capillary Pressure ", J. Pet. Tech., October (1987)1283-1300.

[14] W. G. Anderson, "Wettability Literature Survey-Part 5: The Effects of Wettability on Relative Permeability", J. Pet. Tech., November (1987)1453-1468.

[15] W. G. Anderson, "Wettability Literature Survey-Part 6: The Effects of Wettability on Water Flooding", SPE 16471, 1987.

[16] P. G. Nutting, "Some Physical and Chemical Properties of Reservoir Rocks Bearing on the Accumulation and Discharge of Oil", Problems of Petroleum Geology, W. E. Wrather and F. H. Lahee (Eds), AAPG, Tulsa (1934) 825-832. 
[17] K. H. Anderson, "Discussion of Nature and Importance of Surface Forces inProduction of Petroleum", Drill and Prod. Prac., API, New York City, (1939) 442-448.

[18] S. S. Marsden and S. Khan, "The Wettability of the Bradford Sand. I.", Procedure Monthly (May 1962) 26, No. 5, 2-5.

[19] S. S. Marsden and S. Khan, "The Wettability of the Bradford Sand. II: Phyrolysis Chromatography Studies", Procedure Monthly (June 1965) 29, No. 6, 10-14.

[20] D. L. Katz, "Possibilities of Secondary Recovery for the Oklahama City Wilcox Sand", Trans. AIME, 146 (1942) 28-43.

[21] L. E. Trieber, D. L. Archer, and W. W. Owens, "A Laboratory Evaluation of the Weattability of Fifty Oil Producing Reservoirs", SPEJ (Dec. 1972) 531-540.

[22] G. V. Chilingar and T. F. Yen, "Some Notes on Wettability and Relative Permeabilities of Carbonate Reservoir Rocks, II.", Energy Sources, 7 (1983) 67-75.

[23] R. A. Salathiel, "Oil Recovery by Surface Film Drainage in Mixed-Wettability Rocks", J. Pet. Tech., Oct. (1973) 1216-1224.

[24] A. C. Hall, S. H. Collins and J. C. Melrose, "Stability of Aqueous Wetting Films In Athabasca Tar Sands", SPEJ, 2 (1983) 249-259.

[25] J. C. Melrose, "Interpretation of Mixed Wettability States in Reservoir Rocks", SPE 1097, 1982.

[26] F. F. Craig, "The Reservoir Engineering Aspect of Water-flooding", Monograph Series, SPE, Richardson, TX (1971) 3.

\section{AUTHORS' BIOGRAPHY}

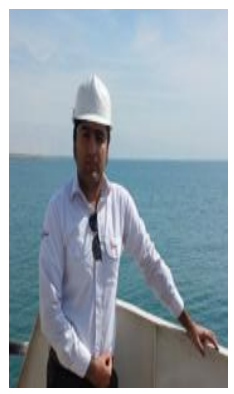

discrepancies.

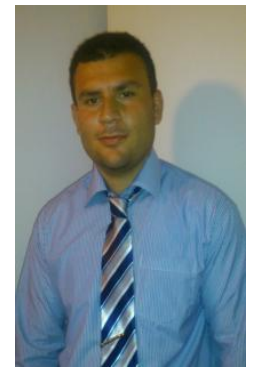

Afshin Davarpanah, Master degree of Petroleum Engineering at Islamic Azad University, Tehran science and research Branch. My current interests in petroleum engineering sciences include a full-field study of Data Gathering, Reservoir Simulation, History Matching and Prediction. Data gathering stage mainly consisted of Well Logging, Coring, Seismic Survey, Geological Survey and DST (or other well tests). History Matching is an extremely crucial stage in full field study in order to get a more reliable prediction of the reservoir behavior. There are always some data which do not match with the true condition of the reservoir. What I did at this stage as a petroleum engineer was to simulate and find the unmatched data and resolve the

M. Mehdi Nasssabeh, received his bachelor degree in Petroleum Production Engineering from the science and research branch of the Azad University in Tehran, Iran and Master of engineering in petroleum drilling operation branch of the Azad University in Omidiyeh, Iran in 2013 and 2017 respectively. I have been working as a commission engineer in the oil and gas industry. Between 2011 and 2013, I completed several training courses including a training course in Professional Reservoir Simulation such as Flogrid, Eclipse 100, PVTi, Eclipse Office, Floviz, VFPi, and another course such as piping technical office and application of Excel engineering, I have an advanced and practical knowledge of computer-based geological modelling of oil fields using Eclipse software and constructed static and dynamic models in reservoir simulation to determine and predict reservoir behavior. I also keeping myself up to date by using latest technical documents and journal articles.

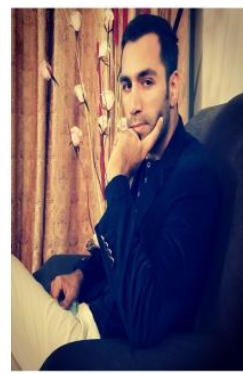

Mojtaba Zarei, Master degree of ChemistryEngineering at Islamic Azad University, Shahreza Branch. My current interests in Chemistry engineering sciences include a full-field study of Data Gathering, Process Simulation, and Enhanced Oil Recovery Methods. As a ChemistryEngineer, I systematically used my knowledge and experience to analyze the situation and then define, design and implement a method to reduce the environmental effects by reducing the unnecessary burning of gases at the flares. 